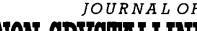

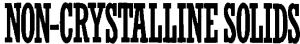

\section{The structural transformation and properties of spin-on poly(silsesquioxane) films by thermal curing}

\author{
Wei-Chih Liu ${ }^{\text {a }}$, Chang-Chung Yang ${ }^{\text {a }}$, Wen-Chang Chen ${ }^{\mathrm{a}, *}$, Bao-Tong Dai ${ }^{\mathrm{b}}$, \\ Ming-Shih Tsai ${ }^{\mathrm{b}}$ \\ a Department of Chemical Engineering, National Taiwan University, Taipei 106, Taiwan \\ ${ }^{\mathrm{b}}$ National Nano Device Laboratories, National Science Council, Hsinchu 300, Taiwan
}

Received 4 September 2001; received in revised form 11 March 2002

\begin{abstract}
In this study, the structural transformation and properties of five commercially available poly(silsesquioxanes) by thermal curing were investigated, including poly(hydrogen silsesquioxanes) (HSQ and T12), and poly(methylsilsesquioxanes) (MSQ, T7 and T9). These materials with a different cage/network ratio and side groups ( $\mathrm{Si}-\mathrm{H}$ and $\mathrm{Si}-$ $\mathrm{CH}_{3}$ ). The FTIR spectra show that the poly(silsesquioxane) films have different contents of the $\mathrm{Si}-\mathrm{O}-\mathrm{Si}$ cage and network structures, which significantly affects the refractive index and dielectric constant. The shifting of the $\mathrm{Si}-\mathrm{O}-\mathrm{Si}$ network band in the FTIR spectra can be correlated with their molecular structures. The refractive indices and dielectric constants of the studied poly(silsesquioxane) films increase with increasing the $\mathrm{Si}-\mathrm{O}-\mathrm{Si}$ network content. The retention of the $\mathrm{Si}-\mathrm{H}$ or $\mathrm{Si}-\mathrm{CH}_{3}$ side group suggests the existence of the cage structures in the poly(silsesquioxane) films. The $\mathrm{Si}-$ $\mathrm{O}-\mathrm{Si}$ cage structure results in a larger free volume than the $\mathrm{Si}-\mathrm{O}-\mathrm{Si}$ network structure in the poly(silsesquioxane) films and thus reduces the refractive index and dielectric constant. It is supported by the porosity result. The order of the refractive index in the studied poly(silsesquioxanes) films is T12 > HSQ for the $\mathrm{Si}-\mathrm{H}$ side group and T7 $>$ T9 $>$ MSQ with the $\mathrm{Si}-\mathrm{CH}_{3}$ side group, which can be correlated with the $\mathrm{Si}-\mathrm{O}-\mathrm{Si}$ network content. The poly(silsesquioxane) film with the $\mathrm{Si}-\mathrm{CH}_{3}$ side group has a lower refractive index than the $\mathrm{Si}-\mathrm{H}$ side group at the same $\mathrm{Si}-\mathrm{O}-\mathrm{Si}$ network content, which is probably due to the steric hindrance effect of the $\mathrm{CH}_{3}$ group.
\end{abstract}

(c) 2002 Elsevier Science B.V. All rights reserved.

\section{Introduction}

Poly(silsesquioxanes) (POSS) such as hydrogen silsesquioxane (HSQ), methyl silsesquioxane (MSQ), and hydrido-organo siloxane polymer

\footnotetext{
${ }^{*}$ Corresponding author. Tel.: +886-2 2362 8398; fax: +886-2 23623040.

E-mail address: chenwc@ms.cc.ntu.edu.tw (W.-C. Chen).
}

(HOSP) have been recognized as potential candidates for low dielectric constant materials [1-10]. The molecular structures of these materials consist a mixed cage/network structure before thermal curing. Part of the cage structures in these materials is transformed to a network structure after thermal curing. The structural modification in the above POSS materials by thermal curing results in a significant variation on their properties, including mechanical properties [11], and dielectric 
properties [12,13], and refractive index [14,15]. Siew et al. studied the microstructures of HSQ in the temperature range of $350-450{ }^{\circ} \mathrm{C}$ [16]. They identified the possible $\mathrm{Si}-\mathrm{H}$ thermal dissociation and the collapse of porous network by the thermogravimetric analysis (TGA) and the Fourier transform infrared (FTIR) spectrophotometer. They proposed four possible stages during curing of the HSQ film: (1) room temperature up to 200 ${ }^{\circ} \mathrm{C}$ : solvent loss; (2) $250-350{ }^{\circ} \mathrm{C}$ : network redistribution and $\mathrm{SiO}_{2}$ formation; (3) $350-435{ }^{\circ} \mathrm{C}: \mathrm{Si}-\mathrm{H}$ thermal dissociation and cage-network redistribution; (4) $>435{ }^{\circ} \mathrm{C}$ (or $450{ }^{\circ} \mathrm{C}$ ): collapse of pore network. The cage/network structural transformation of HSQ by thermal curing has also been reported by Belot et al. [17], Loboda et al. [18], and Albrecht and Blanchette [19]. Our laboratories proposed a two-stage zero-order kinetics on the cage/network transformation on the HSQ films $[14,15]$. The cage structure of the HSQ film transforms into the network structure by thermal curing and results in a significant change on the film properties such as refractive index and dielectric constant. For the POSS films with the $\mathrm{Si}-$ $\mathrm{CH}_{3}$ group, Chua et al. [20] studied the curing behavior of MSQ in the temperature range of 350 $500{ }^{\circ} \mathrm{C}$. They found that the curing reaction of MSQ is an endothermic reaction accompanied by weight loss, shrinkage, and reduction in coefficients of thermal expansion and dielectric constant. Although there were several reports on the structures and properties of the POSS films by thermal curing, most of the above studies focused on one kind of the POSS films. The studies from Siew et al. [16] and our laboratories [14,15] have revealed the possible mechanism for the thermal curing of HSQ. However, a general structureproperty relationship based on different kinds of POSS films by thermal curing has not been fully explored.

In order to investigate the structural transformation and properties of the POSS films by ther-<smiles>[R][Si]1([R])O[Si]([R])([R])O[Si]2([R])O[Si]3([R])O[Si]([R])(O2)O[Si]2([R])O[Si]([R])(O1)O[Si]([R])(O2)O3</smiles>

(a)

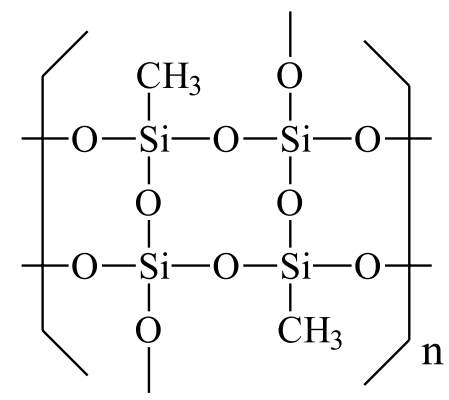

(b)<smiles>CCC12CO[Si]3(C)O[Si](C)(O1)O[Si]1(C)O[Si](C)(O2)O[Si](C)(O3)O1</smiles>

(c)<smiles>CCC1(C)O[SiH]2O[SiH]3O[SiH2](O1)OC(CC)(O3)O2</smiles>

(d)

Fig. 1. The molecular structures of (a) $\mathrm{R}=\mathrm{H}$ for $\mathrm{HSQ}, \mathrm{R}=\mathrm{CH}_{3}$ for MSQ; (b) T7; (c) T9; (d) T12 for the studied poly(silsesquioxanes). 
mal curing, five commercially available POSS films, poly(hydrogen silsesquioxanes) (HSQ and T12), poly(methylsilsesquioxanes) (MSQ, T7 and T9), were studied. The fundamental molecular structures of the studied POSS films are shown in Fig. 1, which include the cage form and the network form. HSQ and T12 are the materials with the $\mathrm{Si}-\mathrm{H}$ side group while MSQ, T7, and T9 with the $\mathrm{Si}-\mathrm{CH}_{3}$ group. The correlations between the cage/network ratio, $\mathrm{Si}-\mathrm{H}$ or $\mathrm{Si}-\mathrm{CH}_{3}$ residues, porosity, refractive index, and dielectric constant of the studied films were investigated.

\section{Experimental}

\subsection{Materials and processing}

HSQ (precursor: Fox 15), and MSQ (precursor: ACCUSPIN 418) were obtained from Dow Corning Corporation (Midland, MI, USA), and Honeywell Inc. (Sunnyvale, CA, USA) respectively. T7, T9, and T12 were purchased from Tokyo Ohka Kogyo (TOK) Co. (Tokyo, Japan). The studied five materials were spun coated on a 4 in. wafer by a spin-on glass (SOG) coater, and baked at different conditions according to Table 1.

\subsection{Characterization}

The chemical structure of the cured films on wafer was characterized by the FTIR. The transformation from the $\mathrm{Si}-\mathrm{O}-\mathrm{Si}$ cage structure to the total $\mathrm{Si}-\mathrm{O}-\mathrm{Si}$ structure (the cage structure + the network structure) was monitored through the variation of the peak area of the $1130 \mathrm{~cm}^{-1}$ peak and the $1000-1250 \mathrm{~cm}^{-1}$ peak. The refractive index and the film thickness of the cured films on wafer were then measured using a refractive index $(n)$ and extinction coefficient $(k)$ analyzer which equipped with the light source of 190-900 nm wavelength. The analyzer detected the reflection of light from thin film and estimated the refractive index and thickness. The porosity $(P)$ of the cured HSQ film was determined by the effective medium approximation (EMA) module of the ellipsometer. The dielectric constant of the HSQ film was obtained by a metal (Al)-insulator-metal (MIM) device. In this measurement, the capacitance of the MIM device was measured by $C-V$ system. The dielectric constant $(k)$ was then calculated from the following formula: $k=c t / A \varepsilon_{0}$, where $c$ is the observed capacitance, $t$ is the film thickness, $A$ is the contacted area with the measured film, and $\varepsilon_{0}$ is the free permittivity. The experimental uncertainties of refractive index, thickness, and dielectric constant are $\pm 0.002, \pm 3 \mathrm{~nm}$, and \pm 0.1 , respectively.

\section{Results}

\subsection{IR spectra}

Fig. 2 shows the FTIR spectra of the studied POSS films after thermal curing. A broad $\mathrm{Si}-\mathrm{O}-\mathrm{Si}$ absorption band in the wave number range of $1000-1250 \mathrm{~cm}^{-1}$ is shown in all five spectra. It suggests the $\mathrm{Si}-\mathrm{O}-\mathrm{Si}$ backbone of the studied films. The absorption bands at 2258 and $830 \mathrm{~cm}^{-1}$ of Fig. 2(a) and (b) are resulted from the $\mathrm{Si}-\mathrm{H}$ bond of the HSQ and T12. The $\mathrm{Si}-\mathrm{CH}_{3}$ absorption bands are found at 1273 and $768 \mathrm{~cm}^{-1}$ for MSQ, 1277 and $780 \mathrm{~cm}^{-1}$ for $\mathrm{T} 7$, and 1273 and $781 \mathrm{~cm}^{-1}$ for T9, respectively. The corresponding $\mathrm{CH}_{3}$ absorption band appears around $2973 \mathrm{~cm}^{-1}$ for the films of MSQ, T7, and T9. There was no $\mathrm{Si}-\mathrm{OH}$ absorption band around $3500 \mathrm{~cm}^{-1}$ in the spectra shown in Fig. 2, which shows the successful curing

Table 1

The conditions for preparing the studied POSS films

\begin{tabular}{lll}
\hline POSS & Processing & Curing conditions \\
\hline HSQ & $3000 \mathrm{rpm}(20 \mathrm{~s})$ & $150{ }^{\circ} \mathrm{C}(1 \mathrm{~min}) \rightarrow 200{ }^{\circ} \mathrm{C}(1 \mathrm{~min}) \rightarrow 300{ }^{\circ} \mathrm{C}(1 \mathrm{~min}) \rightarrow 400{ }^{\circ} \mathrm{C}\left(1 \mathrm{~h}, \mathrm{~N}_{2}\right)$ \\
T12 & $3000 \mathrm{rpm}(20 \mathrm{~s})$ & $80{ }^{\circ} \mathrm{C}(1 \mathrm{~min}) \rightarrow 150{ }^{\circ} \mathrm{C}(1 \mathrm{~min}) \rightarrow 200{ }^{\circ} \mathrm{C}(1 \mathrm{~min}) \rightarrow 400{ }^{\circ} \mathrm{C}\left(30 \mathrm{~min}, \mathrm{~N}_{2}\right)$ \\
MSQ & $3000 \mathrm{rpm}(20 \mathrm{~s})$ & $180{ }^{\circ} \mathrm{C}(1 \mathrm{~min}) \rightarrow 180{ }^{\circ} \mathrm{C}(1 \mathrm{~min}) \rightarrow 250{ }^{\circ} \mathrm{C}(1 \mathrm{~min}) \rightarrow 400{ }^{\circ} \mathrm{C}\left(1 \mathrm{~h}, \mathrm{~N}_{2}\right)$ \\
T7 & $3000 \mathrm{rpm}(20 \mathrm{~s})$ & $80{ }^{\circ} \mathrm{C}(1 \mathrm{~min}) \rightarrow 150{ }^{\circ} \mathrm{C}(1 \mathrm{~min}) \rightarrow 200{ }^{\circ} \mathrm{C}(1 \mathrm{~min}) \rightarrow 400{ }^{\circ} \mathrm{C}\left(30 \mathrm{~min}, \mathrm{~N}_{2}\right)$ \\
T9 & $3000 \mathrm{rpm}(20 \mathrm{~s})$ & $100{ }^{\circ} \mathrm{C}(1 \mathrm{~min}) \rightarrow 180{ }^{\circ} \mathrm{C}(1 \mathrm{~min}) \rightarrow 250{ }^{\circ} \mathrm{C}(1 \mathrm{~min}) \rightarrow 400{ }^{\circ} \mathrm{C}\left(30 \mathrm{~min}, \mathrm{~N}_{2}\right)$ \\
\hline
\end{tabular}




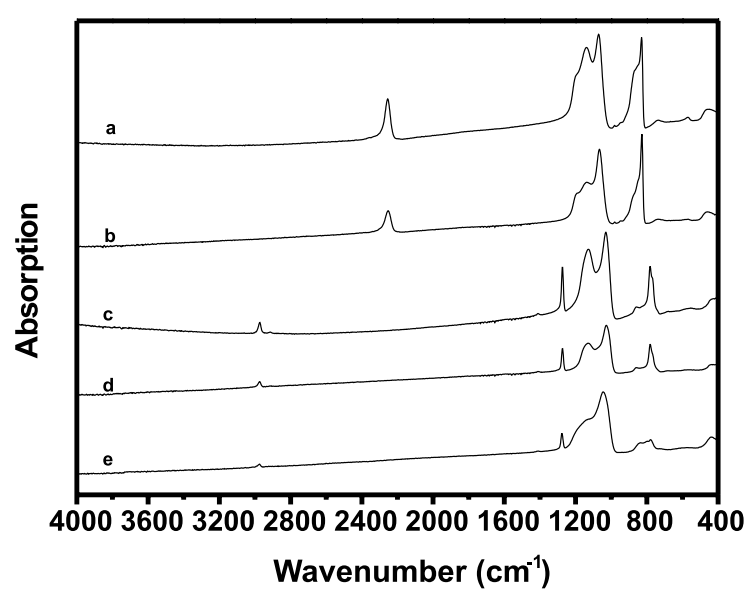

Fig. 2. The FTIR spectra of the studied POSS films in the wave number range of $400-4000 \mathrm{~cm}^{-1}$. (a) HSQ; (b) T12; (c) MSQ; (d) T9; (e) T7.

of the POSS films from their precursor solutions. An interesting feature for the FTIR spectra of the studied polymers is the splitting of the $\mathrm{Si}-\mathrm{O}-\mathrm{Si}$ absorption band into two bands around 1030 1070 and $1130 \mathrm{~cm}^{-1}$, as shown in Fig. 3. These two bands can be assigned to the $\mathrm{Si}-\mathrm{O}-\mathrm{Si}$ network and $\mathrm{Si}-\mathrm{O}-\mathrm{Si}$ cage structures of the POSS films, respectively $[14,15,18,19]$. The absorption band of the $\mathrm{Si}-\mathrm{O}-\mathrm{Si}$ network structure is found at 1070 $\mathrm{cm}^{-1}$ in the spectra of HSQ and T12. By replacing

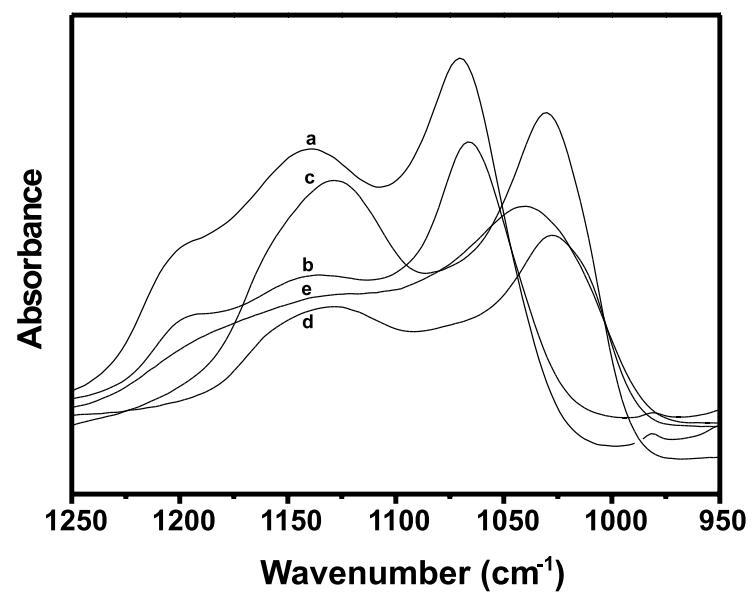

Fig. 3. The FTIR spectra of the studied POSS films in the wave number range of $950-1250 \mathrm{~cm}^{-1}$. (a) HSQ; (b) T12; (c) MSQ; (d) T9; (e) T7.

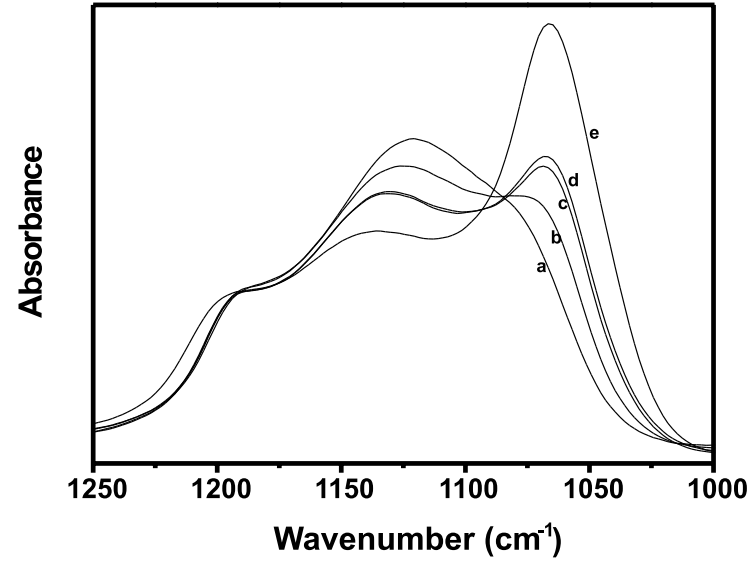

Fig. 4. The FTIR spectra of a typical HSQ film at different baking conditions in the wave number range of $1000-1250$ $\mathrm{cm}^{-1}$. (a) as spun-on; (b) $80{ }^{\circ} \mathrm{C}$; (c) $150{ }^{\circ} \mathrm{C}$; (d) $200{ }^{\circ} \mathrm{C}$; (e) 400 ${ }^{\circ} \mathrm{C}$.

the $\mathrm{Si}-\mathrm{H}$ band with the $\mathrm{Si}-\mathrm{CH}_{3}$ band, the $\mathrm{Si}-\mathrm{O}-\mathrm{Si}$ network absorption band shifts to $1046 \mathrm{~cm}^{-1}$ of T7, and $1030 \mathrm{~cm}^{-1}$ of MSQ and T9. The FTIR study shows the prepared POSS films have the molecular composition of mixed cage and network structures. Fig. 4 shows the FTIR spectra of a typical HSQ film at different stages of curing temperature. The peak at $1130 \mathrm{~cm}^{-1}$ decreases with increasing curing temperature, which is assigned to the cage structure. However, the peak at $1070 \mathrm{~cm}^{-1}$ shows an opposite trend, which is assigned to the network structure. It suggests that the transformation of the cage/network structure is very sensitive to the curing temperature.

\subsection{Structure-property relationships}

In Fig. 5, the HSQ-1 to HSQ-5 mean that five different HSQ samples were baked in the furnace at $400{ }^{\circ} \mathrm{C}$. However, it was found that the structure and properties of the cured HSQ samples show a significant variation because of the deviation of the furnace temperature. Fig. 5 shows the variation of the refractive indices of the five HSQ films with the FTIR peak ratios of the $\mathrm{Si}-\mathrm{O}-\mathrm{Si}$ network structure and the $\mathrm{Si}-\mathrm{H}$ bond to the total $\mathrm{Si}-\mathrm{O}-\mathrm{Si}$ structure, respectively. The total $\mathrm{Si}-\mathrm{O}-\mathrm{Si}$ absorption band is in the wave number range of $1000-1250 \mathrm{~cm}^{-1}$, 


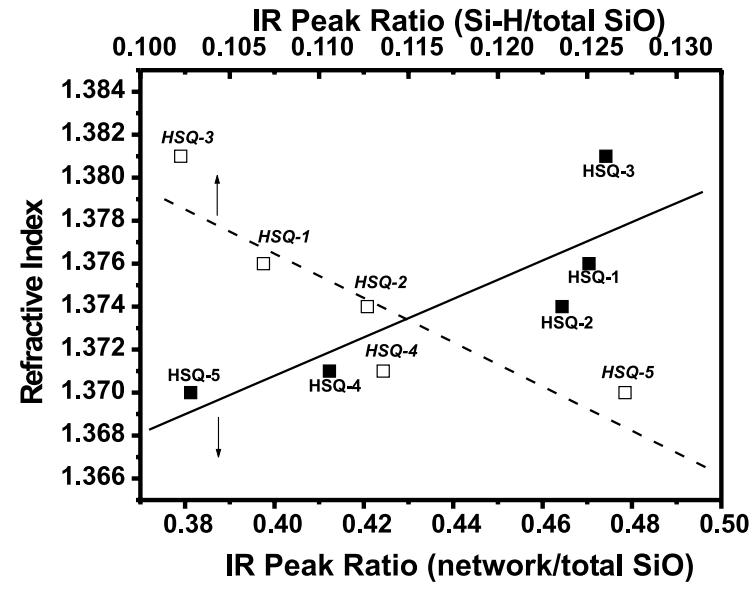

Fig. 5. Variation of the refractive index of five HSQ films with the FTIR peak ratio of the network $\mathrm{Si}-\mathrm{O}-\mathrm{Si}$ structure and the $\mathrm{Si}-\mathrm{H}$ bond to the total $\mathrm{Si}-\mathrm{O}-\mathrm{Si}$ peaks, respectively.

which includes the absorption bands of the cage and network structures of the $\mathrm{Si}-\mathrm{O}-\mathrm{Si}$ bond. The refractive index of the studied HSQ films increases with increasing the ratio of the network structure but decreases with increasing the $\mathrm{Si}-\mathrm{H}$ content in Fig. 5. Fig. 6 shows the variation of dielectric constant with the ratio of the network structure and the $\mathrm{Si}-\mathrm{H}$ bond, respectively. This figure exhibits a similar trend as that of Fig. 5. It illustrates

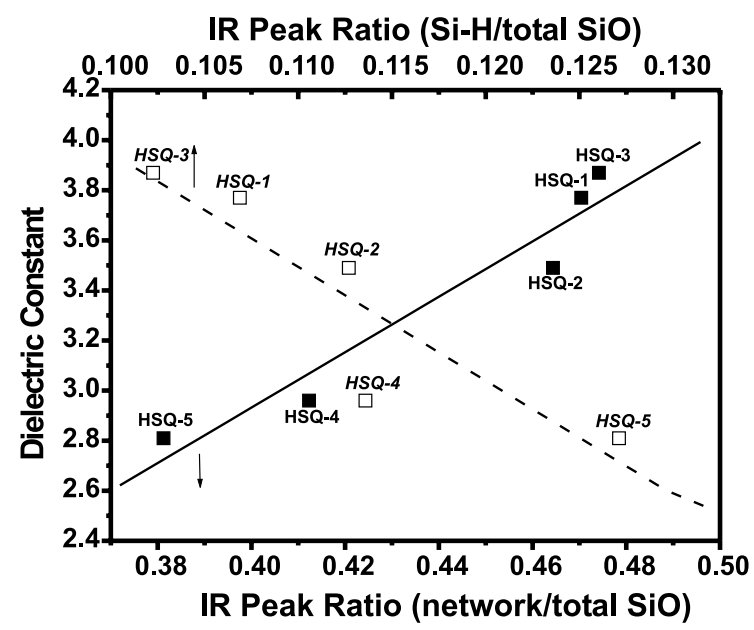

Fig. 6. Variation of the dielectric constant of five HSQ films with the FTIR peak ratio of the network $\mathrm{Si}-\mathrm{O}-\mathrm{Si}$ structure and the $\mathrm{Si}-\mathrm{H}$ bond to the total $\mathrm{Si}-\mathrm{O}-\mathrm{Si}$ peaks, respectively. the increasing of dielectric constant from 2.81 to 3.77 with increasing the content of the network structure and decreasing the $\mathrm{Si}-\mathrm{H}$ bond in the cured HSQ films. In Figs. 7 and 8, it shows the porosity decreases from $16.5 \%$ to $12.3 \%$ with increasing the content of the network structure in the cured HSQ films and also illustrates the increase of the refractive index and dielectric constant of the HSQ films.

A similar observation on the structure and properties relationships is found on the cured poly(silsesquioxane) films with those of the HSQ films. The MSQ-1 $\sim 5$, T7-1 4, T9-1 5, and

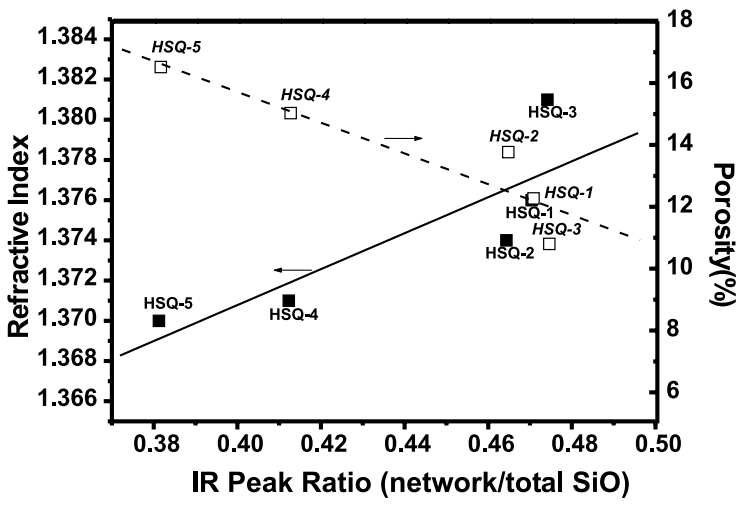

Fig. 7. Variation of porosity and refractive index of five HSQ films with the FTIR peak ratio of the network $\mathrm{Si}-\mathrm{O}-\mathrm{Si}$ structure to the total $\mathrm{Si}-\mathrm{O}-\mathrm{Si}$ peaks.

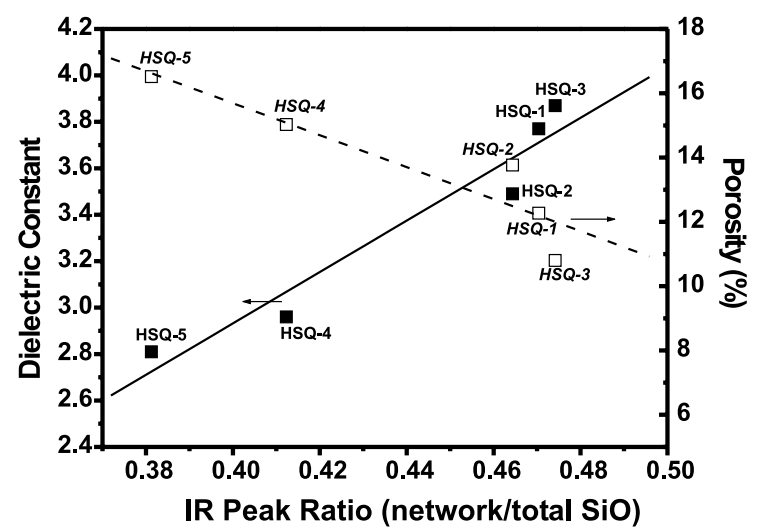

Fig. 8. Variation of porosity and dielectric constant of five HSQ films with the FTIR peak ratio of the network $\mathrm{Si}-\mathrm{O}-\mathrm{Si}$ structure to the total $\mathrm{Si}-\mathrm{O}-\mathrm{Si}$ peaks. 


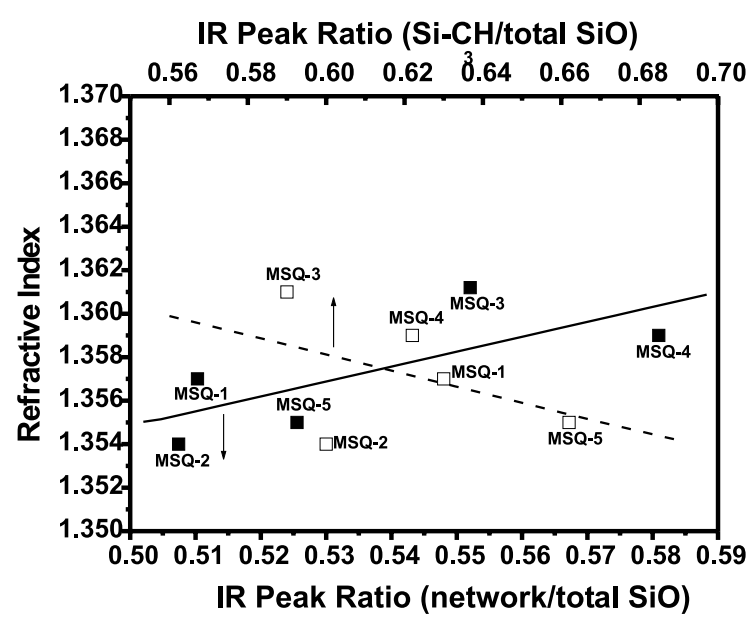

Fig. 9. Variation of refractive index of five MSQ films with the FTIR peak ratio of the network $\mathrm{Si}-\mathrm{O}-\mathrm{Si}$ structure and the $\mathrm{Si}-$ $\mathrm{CH}_{3}$ bond to the total $\mathrm{Si}-\mathrm{O}-\mathrm{Si}$ peaks.

T12-1 $\sim 5$ mean cured poly(silsesquioxanes) due to the variation of furnace temperatures. Fig. 9 shows the variation of the refractive indices of the five MSQ films with the FTIR peak ratio of the Si$\mathrm{O}-\mathrm{Si}$ network structure and the $\mathrm{Si}-\mathrm{CH}_{3}$ bond to the total $\mathrm{Si}-\mathrm{O}-\mathrm{Si}$ structure. The refractive index increases from 1.354 to 1.361 as increasing the $\mathrm{Si}-$ $\mathrm{O}-\mathrm{Si}$ network ratio and decreasing the $\mathrm{Si}-\mathrm{CH}_{3}$ ratio. The trend is similar to that of HSQ. How-

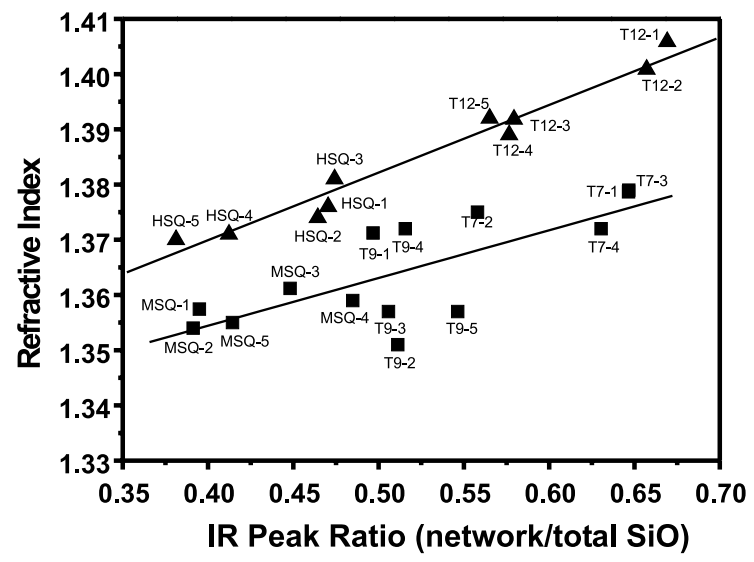

Fig. 10. Variation of refractive index of the studied HSQ, T12, MSQ, T7, and T9 films with the FTIR peak ratio of the network $\mathrm{Si}-\mathrm{O}-\mathrm{Si}$ structure to the total $\mathrm{Si}-\mathrm{O}-\mathrm{Si}$ peaks. ever, the variation of the refractive index and the molecular structures is not as significant as the case of HSQ. Fig. 10 shows the variation of the refractive index of the cured POSS films with the FTIR peak ratio of the $\mathrm{Si}-\mathrm{O}-\mathrm{Si}$ network structure to the total $\mathrm{Si}-\mathrm{O}-\mathrm{Si}$ structure. For the studied POSS films, it has a general trend on the variation of the refractive index with the content of the network structure. That is, the refractive index increases with increasing the $\mathrm{Si}-\mathrm{O}-\mathrm{Si}$ network content. Furthermore, the order of the refractive index at the same $\mathrm{Si}-\mathrm{O}-\mathrm{Si}$ network ratio is T12 $>$ HSQ $>$ T7 $>$ T9 $>$ MSQ. The POSS films with the $\mathrm{Si}-\mathrm{CH}_{3}$ side group (T7, T9, MSQ) have a lower refractive index than the $\mathrm{Si}-\mathrm{H}$ side group (HSQ, T12).

\section{Discussion}

\section{1. $\mathrm{Si}-\mathrm{O}-\mathrm{Si}$ structure}

In FTIR spectra, the Si-O-Si network absorption was shift to a lower wave number for the $\mathrm{Si}-$ $\mathrm{CH}_{3}$ bond than that of the $\mathrm{Si}-\mathrm{H}$ bond in the studied films. This is because the $\mathrm{CH}_{3}$ group results in a steric hindrance of the molecular structure and thus decreases the polarization of $\mathrm{Si}-\mathrm{O}-\mathrm{Si}$ network structure. Furthermore, note that the $\mathrm{CH}_{3}$ content of $\mathrm{T} 7, \mathrm{~T} 9$, and MSQ are $11 \%$ and $20 \%, 22 \%$, respectively. Therefore, the $\mathrm{Si}-\mathrm{O}-\mathrm{Si}$ network absorption of MSQ shifts to a lower wave number. The cage structure of the HSQ film is transformed to the network structure by thermal curing, as shown in Fig. 4, suggests that the transformation of the cage/network structure is very sensitive to the curing temperature. For the other poly(silsesquioxanes) in our study have the same tendency.

\subsection{Structure-property relationship}

For HSQ, the $\mathrm{Si}-\mathrm{H}$ bond is very sensitive to the curing temperature. The bond cleavage of the $\mathrm{Si}-$ $\mathrm{H}$ bond results in the collapse of the cage structure and then the formation of the dense $\mathrm{Si}-\mathrm{O}-\mathrm{Si}$ network structure. The higher $\mathrm{Si}-\mathrm{H}$ content suggests 
the higher retention of the cage structure in the HSQ films. The cage structure results in a larger free volume of the molecular structure and thus results in a lower refractive index than the network structure. This result can be supported by the dielectric constant of the HSQ film. Since the dielectric constant is generally proportional to the refractive index, the results in Figs. 5 and 6 show the importance of the ratio of the cage/network structure on the properties of the HSQ films. The porosities of the five HSQ samples can further support the effects of the free volume for the ratio of the cage/network structure on the properties of the HSQ films. A similar observation on the structure and properties relationships is found on the MSQ films with those of the HSQ films. However, the variation of the refractive index and the molecular structures is not as significant as the case of HSQ. It suggests that the $\mathrm{Si}-\mathrm{CH}_{3}$ bond cleavage is not as thermal sensitive as the $\mathrm{Si}-\mathrm{H}$ bond. The similar results could be found for the other poly(silsesquioxanes) in our study.

For the refractive index result of all poly(silsesquioxanes) in this study, the POSS films with the $\mathrm{Si}-\mathrm{CH}_{3}$ side group (T7, T9, MSQ) have a lower refractive index than the $\mathrm{Si}-\mathrm{H}$ side group (HSQ, T12). It is probably because the materials with the $\mathrm{CH}_{3}$ group results in a steric hindrance in the chemical structure, and thus has a larger free volume than the materials with the $\mathrm{Si}-\mathrm{H}$ group. Furthermore, the $\mathrm{Si}-\mathrm{CH}_{3}$ content of $\mathrm{T} 7$, $\mathrm{T} 9$, and MSQ are $11 \%, 20 \%$, and $22 \%$, respectively. This explains the order of the refractive index shown in Fig. 10.

\section{Conclusions}

The structural transformation and properties of five commercially available POSS by thermal curing were studied. The POSS films by thermal curing have different $\mathrm{Si}-\mathrm{O}-\mathrm{Si}$ cage/network contents, which significantly affect the refractive index and dielectric constant. The refractive indices and dielectric constants of the studied POSS films decrease with increasing the $\mathrm{Si}-\mathrm{O}-\mathrm{Si}$ network content. It is supported by the porosity result. The order of the refractive index in the studied POSS films is T12 $>$ HSQ for the $\mathrm{Si}-\mathrm{H}$ side group and $\mathrm{T} 7>\mathrm{T} 9>\mathrm{MSQ}$ with the $\mathrm{Si}-\mathrm{CH}_{3}$ side group, which can be correlated with the $\mathrm{Si}-\mathrm{O}-\mathrm{Si}$ network content. The POSS film with the $\mathrm{Si}-\mathrm{CH}_{3}$ side group has a lower refractive index than the $\mathrm{Si}-\mathrm{H}$ side group at the same $\mathrm{Si}-\mathrm{O}-\mathrm{Si}$ network content, which is probably due to the steric hindrance effect of the $\mathrm{CH}_{3}$ group.

\section{Acknowledgements}

The authors thank the National Science Council of Taiwan for the financial support of this work. The authors also thank the Dow Corning Corporation, and the Honeywell, Inc. for providing the HSQ and MSQ precursors, respectively.

\section{References}

[1] T.M. Lu, S.P. Murarka, T.S. Kuan, C.H. Ting (Eds.), Low-Dielectric Constant Materials-Synthesis and Applications in Microelectronics, Materials Research Society, Pittsburgh, PA, MRS. Symp. Proc., vol. 381, 1995.

[2] A. Lagendijk, H. Treichel, K.J. Uram, A.C. Jones (Eds.), Low-Dielectric constant Materials II, Materials Research Society, Pittsburgh, PA, MRS Symp. Proc., vol. 443, 1996.

[3] C. Case, P. Kohl, T. Kikkawa, W.W. Lee (Eds.), LowDielectric Constant Materials III, Materials Research Society, Pittsburgh, PA, MRS Symp. Proc., vol. 476, 1997.

[4] C. Chiang, P.S. Ho, T.M. Lu, J.T. Wetzel (Eds.), LowDielectric Constant Materials IV, Materials Research Society, Pittsburgh, PA, MRS Symp. Proc., vol. 511, 1998.

[5] J. Hummel, K. Endo, W.W. Lee, M. Mills, S.Q. Wang (Eds.), Low-Dielectric Constant Materials V, Materials Research Society, Pittsburgh, PA, MRS Symp. Proc., vol. $565,1999$.

[6] W.C. Chen, S.C. Lin, B.T. Dai, M.S. Tsai, J. Electrochem. Soc. 146 (1999) 3004.

[7] W.C. Chen, C.T. Yen, J. Polym. Res. 6 (1999) 197.

[8] W.C. Chen, C.T. Yen, J. Vac. Sci. Technol. B. 18 (2000) 201.

[9] M.J. Loboda, G.A. Toskey, Solid State Technol. 41 (1998) 99.

[10] J.N. Bremmer, Y. Liu, K.G. Gruszynski, F.C. Dall, in: C. Case, P. Kohl, T. Kikkawa, W.W. Lee (Eds.), LowDielectric Constant Materials III, Materials Research Society, Pittsburgh, PA, MRS Symp. Proc., vol. 476, 1997, p. 37.

[11] Y. Liu, F. Dall, in: J. Hummel, K. Endo, W.W. Lee, M. Mills, S.Q. Wang (Eds.), Low-Dielectric Constant Materials V, Materials Research Society, Pittsburgh, PA, MRS Symp. Proc., vol. 565, 1999, p. 267. 
[12] H.C. Liou, J. Pretzer, Thin Solid Films 335 (1998) 186.

[13] R.F. Cook, E.G. Liniger, J. Electrochem. Soc. 146 (1999) 4439.

[14] C.C. Yang, W.C. Chen, L.M. Chen, C.J. Wang, Proc. Nsc. ROC. A 25 (2001) 339.

[15] C.C. Yang, W.C. Chen, J. Mater. Chem. 12 (2002) 1138.

[16] Y.K. Siew, G. Sarkar, X. Hu, A. See, C.T. Chua, J. Electrochem. Soc. 147 (2000) 335.
[17] V. Belot, R. Corriu, D. Leclercq, P.H. Mutin, A. Vioux, Chem. Mater. 3 (1991) 127.

[18] M.J. Loboda, C.M. Grove, R.F. Schneider, J. Electrochem. Soc. 145 (1998) 2861.

[19] M.G. Albrecht, C. Blanchette, J. Electrochem. Soc. 145 (1998) 4019

[20] C.T. Chua, G. Sarkar, X. Hu, J. Electrochem. Soc. 145 (1998) 4007. 